\title{
Saudi Arabia Stock Market Prediction Using Neural Network
}

\author{
Talal Alotaibi, Amril Nazir, Roobaea Alroobaea, Moteb Alotibi, Fasal Alsubeai, Abdullah Alghamdi, \\ Thamer Alsulimani \\ Department of Computer Science, College of Computers and Information Technology \\ Taif University, Taif, KSA \\ amril@tu.edu.sa, r.robai@tu.edu.sa
}

\begin{abstract}
Artificial neural networks became one of the most popular methods for forecasting (especially time-series forecasting) due to their ability to model nonlinear functions. One of the common methods for applying the artificial neural network is back propagation method. There have been many studies that have been conducted to apply artificial neural networks in stock market predictions. However, most stock market predictions only focus on US, Europeans and some Asian markets. To our knowledge, there are very few studies in stock market prediction for Saudi market. We tried to explore artificial neural networks using back-propagation algorithm to predict the Saudi market movement. We used the real datasets from the Saudi Stock Exchange (i.e., TADAWUL stock market exchange) and oil historical prices to evaluate the effectiveness of the proposed neural network methods. The results shows the capability of neural networks in predicting the stock exchange movement in Saudi market.
\end{abstract}

Keywords - stock market prediction; Saudi Arabia stock prediction; neural network stock prediction.

\section{INTRODUCTION}

Prediction of stock market is gaining a lot of attention because it can help financial organization and investors to make better investment decisions. Many researchers in artificial intelligence community have proposed diverse kind of technical indicators, fundamental analysis, and statistical techniques such as Regression, and genetic algorithms. However, most of these techniques or the combination techniques were not very successful to predict the stock market movement accurately [1]. However, artificial neural networks showed the opposite especially in the prediction filed and it have become objects of everyday use and have shown to be very effective in many fields such as signal filtering in computer modems, speech recognition and optical character recognition etc. Moreover, neural networks have been currently applied in classification, intelligent control, medicine, pattern analysis, function approximation, weather forecasting etc. This success has proved neural networks as an adequate model and method in real life use cases. Many researchers have also conducted some studies on the utilization of artificial neural networks in predicting the stock markets and they have shown that the approach can provide powerful performance in stock market prediction due to their ability to model nonlinear functions, since most stock markets is complex(nonlinear) and volatile[1, 2]. The powerful ability shown by neural networks are due to: (1) its ability to find a relationships between input and output even if the problem is very complicated and figure out exactly what it has learnt; (2) The new patterns can recognized even if they haven't been in training set; (3) Neural networks has the ability to approximate any function that enables us to learn an intricate relationships between the system input and the output.

There are many research that been conducted in the area using artificial neural networks for stock market predictions. However, to our knowledge, there is a very rare study on stock market prediction on Saudi market. In this work we will examine and present the artificial network technique to predict the Saudi stock market movement. We used real datasets from the TADAWUL stock market exchange to evaluate the effectiveness of the proposed technique. Following section reviews the literature for existing methods.

\section{LITERATURE REVIEW}

The studies of forecasting the movement of the stock market have been growing in recent years. One of the methods that have been used for predicting the stock market movements and prices is artificial neural network (ANN).Yao, Jingtao, and Chew Lim Tan [3] explains that back-propagation network used in his study has given good results for forecasting. Guresen et al [4] also did research in stock market index prediction using neural networks. Chen et al [11] in their work on predicting the direction of index return for Taiwan stock exchange was a promosing one.

Khoa et al, [11] used a systematic method to investigate if it can predict the stock market price using artificial neural networks with back propagation. A lot of improvement appeared after the integration of the time factors algorithm and profit when we compare it with the classic(traditional) training for Feed Forward Network. Khashei et al [12], used artificial neural networks (ANNs) model for time series forecasting and got prediction with a high degree of accuracy. Chan et al [13], investigate the neural networks to predict Financial Time Series. The experimental results based on historical data it is possible to modeling stock price using three layer neural 
network. Nordberg M and Karlsson S, used ANN for Stock market index prediction trained on foreign markets[14].

Ye, Q and Wei, L. [15], used Wavelet Neural Network for Prediction of Stock Price and the simulation results of Shanghai index data discovered that the improvement changes that is performed on WNN method is effective and the model showed up a good prediction performance. Yao et al, conduct a study on the usage of artificial neural network to perform technical predict of FOREX. It shows that back-propagation network used in the present study [16] has proved to be adequate for forecasting. Guresen et al used the models of artificial neural network in the prediction of stock market index and it shows that the results obtained in ANN was fairly accurate. Leung and Hazem [4] used neural networks for forecasting and trading the Taiwan Stock Index and it shows that the models of neural networks are very useful in forecasting the movement and direction of index return.

Kara et al [9], investigate on the capability of support vector machine and artificial neural networks on the prediction of the direction of the stock price index movement. it showed that the accuracy of ANN model (75.7\%) is better than SVM model (71.5\%). Grigoryan [10] and Ghezelbash [19] designed and implemented artificial neural network System for stock exchange prediction and found that artificial neural network is useful prediction tools for stock market.

Chen, W. H., Shih, J. Y., \& Wu, conducted a research [6] on comparing between artificial neural networks and support vector machines. it showed that both models perform good and it shows that both method had the ability to predict the stock market. Ou, P., and Wang, H. conducted a research on using ten data mining techniques to predicting stock market index movement.

In this work we will examine the applicability of ANN in forecasting the movement of Saudi stock market and analyze the results.

\section{NETWORK MODEL FOR STOCK MARKET PREDICTION}

Generally, ANN have 3 main layers Input Layer, Hidden Layer And Output Layer. Here in our work input layer contains historical prices of TADAWUL index and historical oil price. Normally we use only one hidden layer which will model most of the problems or you can use more than one users. our networks output layer consists of Sunday price Prediction and Monday Price Prediction.

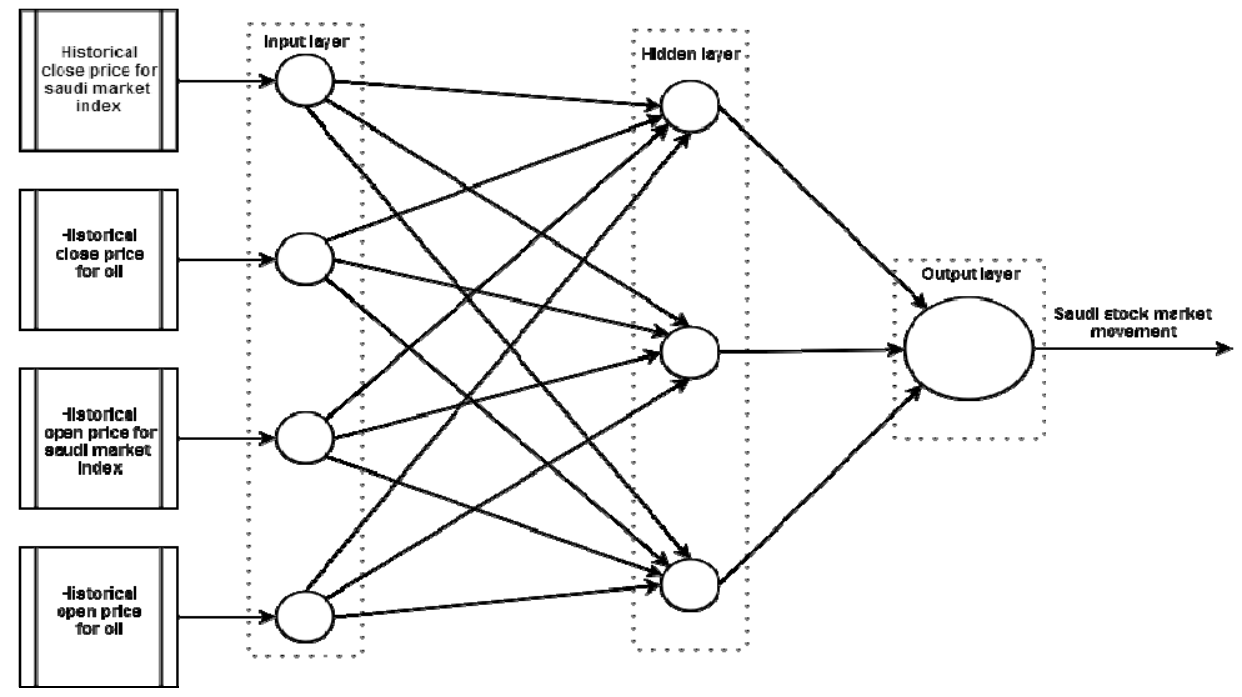

Figure 1. Example for our model [4 inputs, 1 hidden layer, 3 neurons in hidden layer, 1output]

We will use MATLAB program language to help us doing the training machine for predicting Saudi stock market movement [2]. A major drawback of using neural networks is the local minimum and in our work we tried two methods to resolve this issue. First is to increase the number of hidden neuron and the other is to change the value of learning rate. The issue of over fitting can be resolved by correctly identifying the number of hidden neurons and thus can achieve better results.

\section{RESUlTS AND DISCUSSION}

In this section, we present and discuss our experimental results.

A. The impact of using different technical indicators as inputs

We have conducted some experimental studies using the different technical indicators, training and transfer functions to evaluate the performance of our neural network using real historical data from Saudi's stock market and OPEC crude oil prices. Initially, we use open and close prices from the TADAWUL, and the close price for the crude oil price for our neural network training from 2003-2015. The training period is set to 2003-2012, and 
test period is 3 years, from the beginning of 2013 until the end of 2015.We set the topology to be different for each training. This is because we found out that the topology can help us to avoid over fitting problem in some situation. The maximum profit during the test period is $205.16 \%$.

We used different technical indicators on the inputs and we followed steps to see what data can help us to achieve good results and also to get better accuracy and profit for each step. Table 1 summarizes the performance of our neural networks in terms of the highest profits and accuracy using different indicators as our input and training data. Below, we summarize our research findings based on the different indicators used.

TABLE 1: The highest accuracy achieved by using different inputs

\begin{tabular}{|c|c|c|c|c|}
\hline Inputs & $\begin{array}{c}\text { Training } \\
\text { function }\end{array}$ & Transfer function & $\begin{array}{c}\text { Number of } \\
\text { epochs }\end{array}$ & Highest accuracy \\
\hline TADAWUL Prices & Trainbr & Logsig: hidden layer & 1190 & $80.61 \%$ \\
\hline $\begin{array}{c}\text { Average TADAWUL Prices } \\
\text { with oil }\end{array}$ & Trainbr & Tansig: hidden layer & 1000 & $79.5 \%$ \\
\hline $\begin{array}{c}\text { Momentum(All TADAWUL } \\
\text { prices)/All TADAWUL prices }\end{array}$ & Trainbr & Tansig: hidden layer & 550 & $73 \%$ \\
\hline $\begin{array}{c}\text { Average ten days(All } \\
\text { TADAWUL prices) } \\
\text { /All TADAWUL prices }\end{array}$ & Trainbr & Tansig: hidden layer & 700 & $74 \%$ \\
\hline $\begin{array}{c}\text { Typical price/All TADAWUL } \\
\text { prices }\end{array}$ & Trainbr & Tansig: hidden layer & 300 & $83.61 \%$ \\
\hline $\begin{array}{c}\text { Stochastic K\% D\% } \\
\text { All TADAWUL prices }\end{array}$ & Trainbr & Logsig: hidden layer & 107 & $84.46 \%$ \\
\hline $\begin{array}{c}\text { Weighted close / Typical price } \\
\text { / All TADAWUL prices }\end{array}$ & Trainbr & Tansig: hidden layer & 500 & $84.18 \%$ \\
\hline $\begin{array}{c}\text { MACD(All TADAWUL } \\
\text { prices) }\end{array}$ & Trainbr & Tansig: hidden layer & 300 & $83.42 \%$ \\
\hline $\begin{array}{c}\text { RSI(Close price) /All } \\
\text { TADAWUL prices }\end{array}$ & Trainbr & Logsig: hidden layer & 111 & $83.42 \%$ \\
\hline $\begin{array}{c}\text { Medianprice/Close Price } \\
\text { / Trainbr }\end{array}$ & Tansig: hidden layer & 400 & $83.89 \%$ \\
\hline
\end{tabular}


TABLE 2: The highest profit achieved by using different inputs

\begin{tabular}{|c|c|c|c|c|}
\hline Inputs & $\begin{array}{c}\text { Training } \\
\text { function }\end{array}$ & Transfer function & $\begin{array}{c}\text { Number of } \\
\text { epochs }\end{array}$ & Highest profit \\
\hline TADAWUL Prices & Trainbr & Logsig: hidden layer & 1190 & $162.18 \%$ \\
\hline $\begin{array}{c}\text { Average TADAWUL } \\
\text { Prices with oil }\end{array}$ & Trainbr & Tansig: hidden layer & 1000 & $170.3 \%$ \\
\hline $\begin{array}{c}\text { Momentum(All } \\
\text { TADAWUL prices)/All } \\
\text { TADAWUL prices }\end{array}$ & Trainbr & Tansig: hidden layer & 550 & $168 \%$ \\
\hline $\begin{array}{c}\text { Average ten days(All } \\
\text { TADAWUL prices) }\end{array}$ & Trainbr & Tansig: hidden layer & 800 & $150 \%$ \\
\hline /All TADAWUL prices & Trainbr & Tansig: hidden layer & 500 & $172.3 \%$ \\
\hline $\begin{array}{c}\text { Typical price } \\
\text { Stochastic K\% D\% }\end{array}$ & Trainbr & Logsig: hidden layer & 107 & $172.76 \%$ \\
\hline $\begin{array}{c}\text { Weighted close / Typical } \\
\text { price / All TADAWUL } \\
\text { prices }\end{array}$ & Trainbr & Tansig: hidden layer & 500 & $170.06 \%$ \\
\hline $\begin{array}{c}\text { MACD(Low price) } \\
\text { All TADAWUL prices }\end{array}$ & Trainbr & Tansig: hidden layer & 300 & $171.82 \%$ \\
\hline $\begin{array}{c}\text { RSI(Close price) /All } \\
\text { TADAWUL prices }\end{array}$ & Trainbr & Logsig: hidden layer & $111.6 \%$ \\
\hline $\begin{array}{c}\text { Medianprice/Close Price } \\
\text { TADAWUL prices }\end{array}$ & Trainbr & Tansig: hidden layer & 400 & $170 \%$ \\
\hline
\end{tabular}

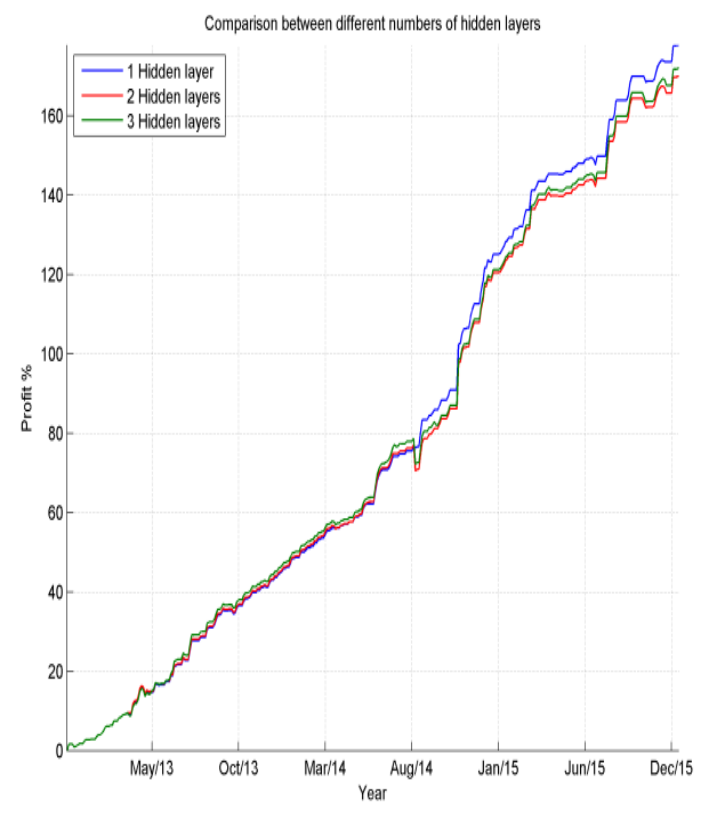

(a)

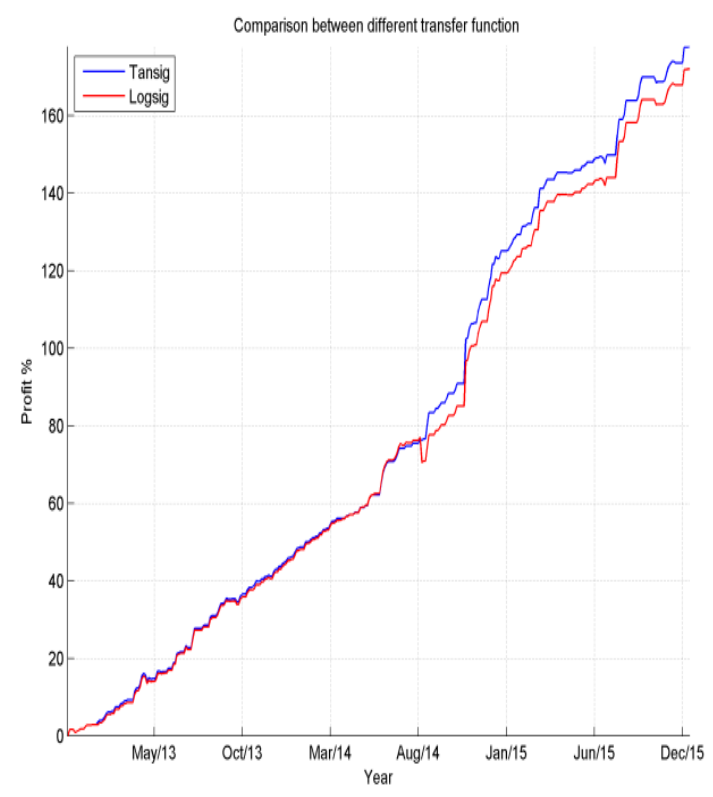

(b)

Figure 2. Profit achieved using (a) different number of hidden layers and (b) different transfer function

From Fig 2(a), it can be observed that the profits vary when we used different number in hidden layer. We can see that the profit was at first almost the same. However, at some point after Aug/14, we can observe that the profits are decreasing when number of hidden layers increases. Based on this finding, we will only use 1 hidden 
layer for our experiments because it is faster to train and most importantly, it generates more profit. From Fig 2 (b)shows the profit achieved using different transfer functions.

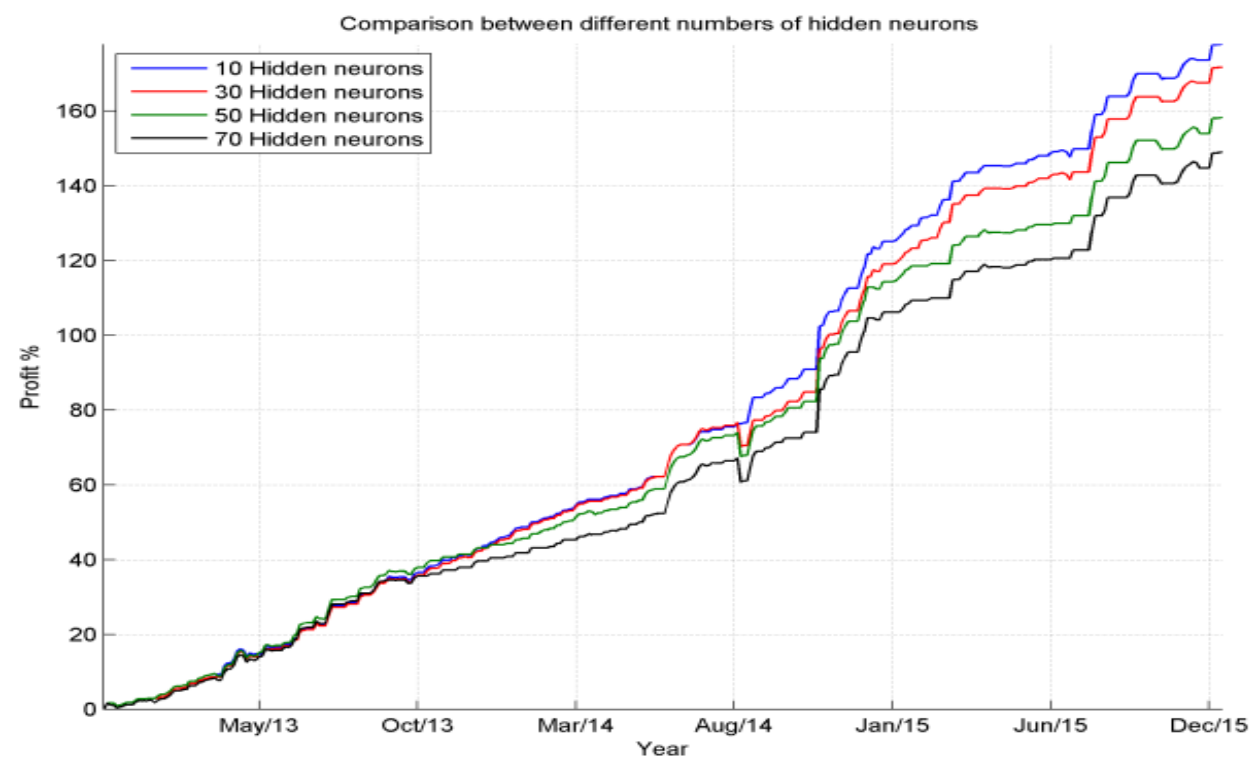

Figure 3: Profit achieved using different number of hidden neurons

From Fig 3 we can see that the when we increase the number of hidden neurons the profit decrease.

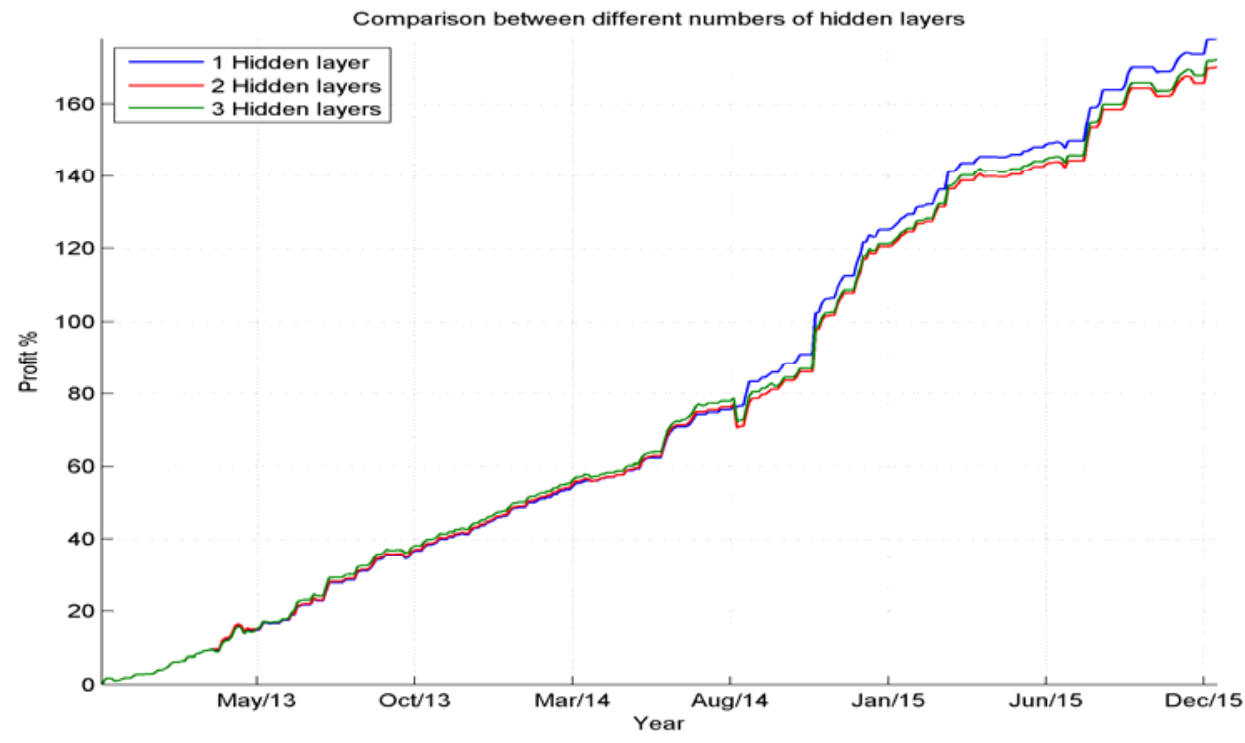

Fig 4: Profit achieved using different number of hidden layers

From Fig 4, it can be observed that the profits vary when we used different number in hidden layer. We can see that the profit was at first almost the same. However, at some point after Aug/14, we can observe that the profits are decreasing when number of hidden layers increases. Based on this finding, we will only use 1 hidden layer for our experiments because it is faster to train and most importantly, it generates more profit.

\section{B. Recession Period}

We aim to stress our network during recession period from the beginning of 2008 until the end of 2009. This will be our test data and our training will be from the beginning of 2003 until 2007. Table 3 illustrates the highest accuracy and profits for the best three inputs. Further, Fig 4 shows the comparison between actual price and predicted price using the training function. 
TABLE 3: The highest accuracy and profits for the best three inputs

\begin{tabular}{|c|c|c|c|c|c|}
\hline Inputs & $\begin{array}{c}\text { Training } \\
\text { function }\end{array}$ & $\begin{array}{c}\text { Transfer } \\
\text { function }\end{array}$ & $\begin{array}{c}\text { Number of } \\
\text { epochs }\end{array}$ & Accuracy & Profit \\
\hline $\begin{array}{c}\text { Medianprice/Cl } \\
\text { ose Price (Mp\& } \\
\text { CP) }\end{array}$ & Trainbr & $\begin{array}{c}\text { Logsig: hidden } \\
\text { layer }\end{array}$ & 250 & $74.86 \%$ & $135.02 \%$ \\
\hline $\begin{array}{c}\text { Weighted close } \\
\text { / Typical price / } \\
\text { All TADAWUL } \\
\text { prices } \\
\text { (Wc \& Tp \& } \\
\text { Tps) }\end{array}$ & Trainbr & $\begin{array}{c}\text { Logsig: hidden } \\
\text { layer }\end{array}$ & 650 & $71.72 \%$ & $115.68 \%$ \\
\hline $\begin{array}{c}\text { Stochastic K\% } \\
\text { D\% } \\
\text { / All } \\
\text { TADAWUL } \\
\text { prices } \\
\text { (K\% \& D \& } \\
\text { Tps) }\end{array}$ & Trainbr & $\begin{array}{c}\text { Logsig: hidden } \\
\text { layer }\end{array}$ & 600 & $74.34 \%$ & $120.11 \%$ \\
\hline
\end{tabular}

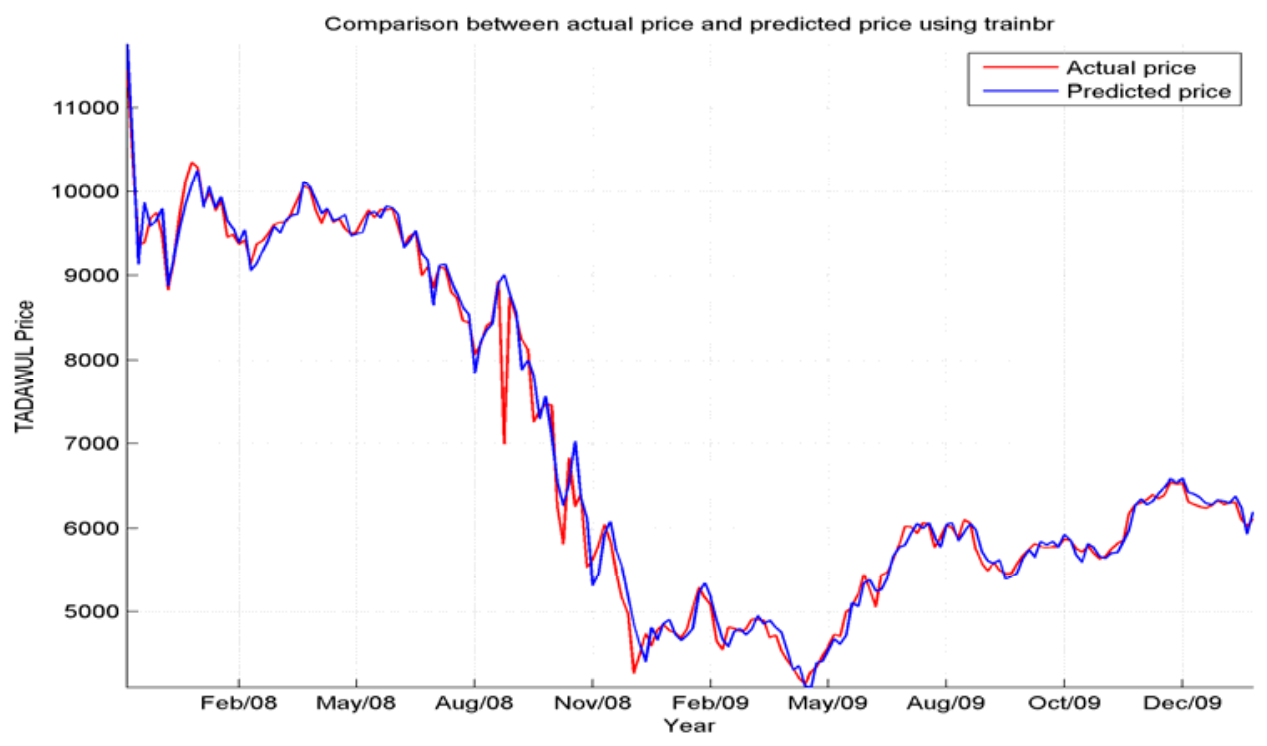

Fig 5. Comparison between actual and predicted price using trainbr in recession period

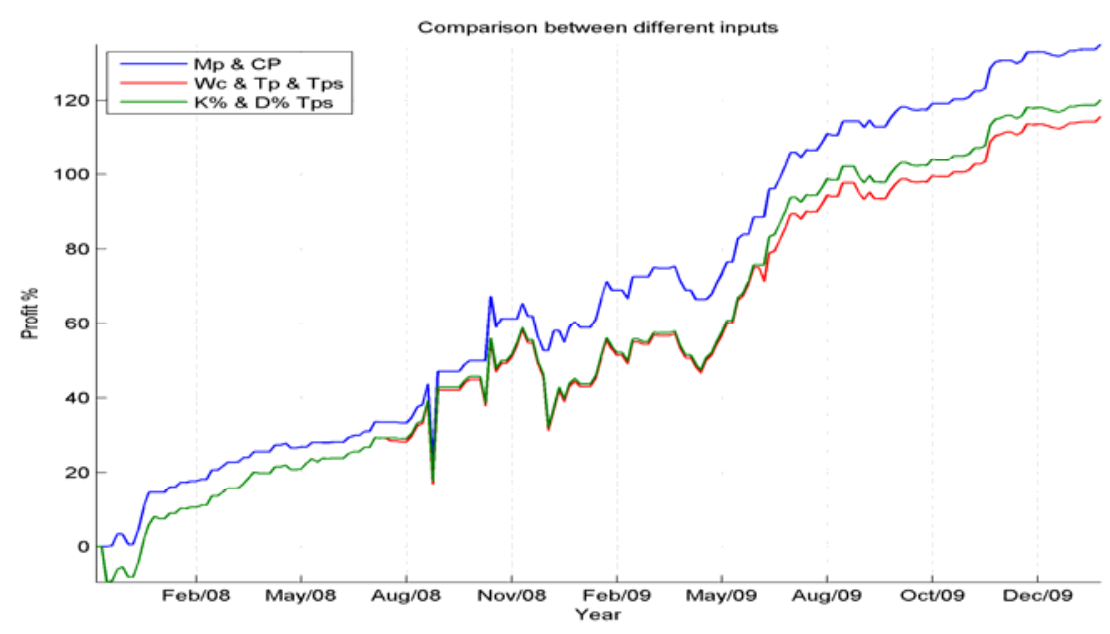

Figure 6: Best three inputs were used to test during recession period for the profit 


\section{The impact of training function on performance}

Table 4 illustrate the highest accuracy achieved based on the different training and transfer functions from our experimental studies. Fig 5 further provides ccomparisons between actual and predicted price using trainbr, trainrp , trainbrscg and trainbfg. Further, Fig 6 shows the profit achieved using different training functions.

\begin{tabular}{|c|c|c|c|c|}
\hline $\begin{array}{c}\text { Training } \\
\text { function }\end{array}$ & Transfer function & $\begin{array}{c}\text { Number of } \\
\text { epochs }\end{array}$ & Highest accuracy & Highest profit \\
\hline Trainbr & Tansig: hidden layer & 400 & $84.46 \%$ & $177.6 \%$ \\
\hline Trainrp & Tansig: hidden layer & 400 & $75.14 \%$ & $150.2 \%$ \\
\hline Trainscg & Tansig: hidden layer & 700 & $76.52 \%$ & $157.74 \%$ \\
\hline Trainbfg & Logsig: hidden layer & 1000 & $62.42 \%$ & $116.83 \%$ \\
\hline
\end{tabular}

TABLE 4: The highest accuracy and profit achieved by different training function
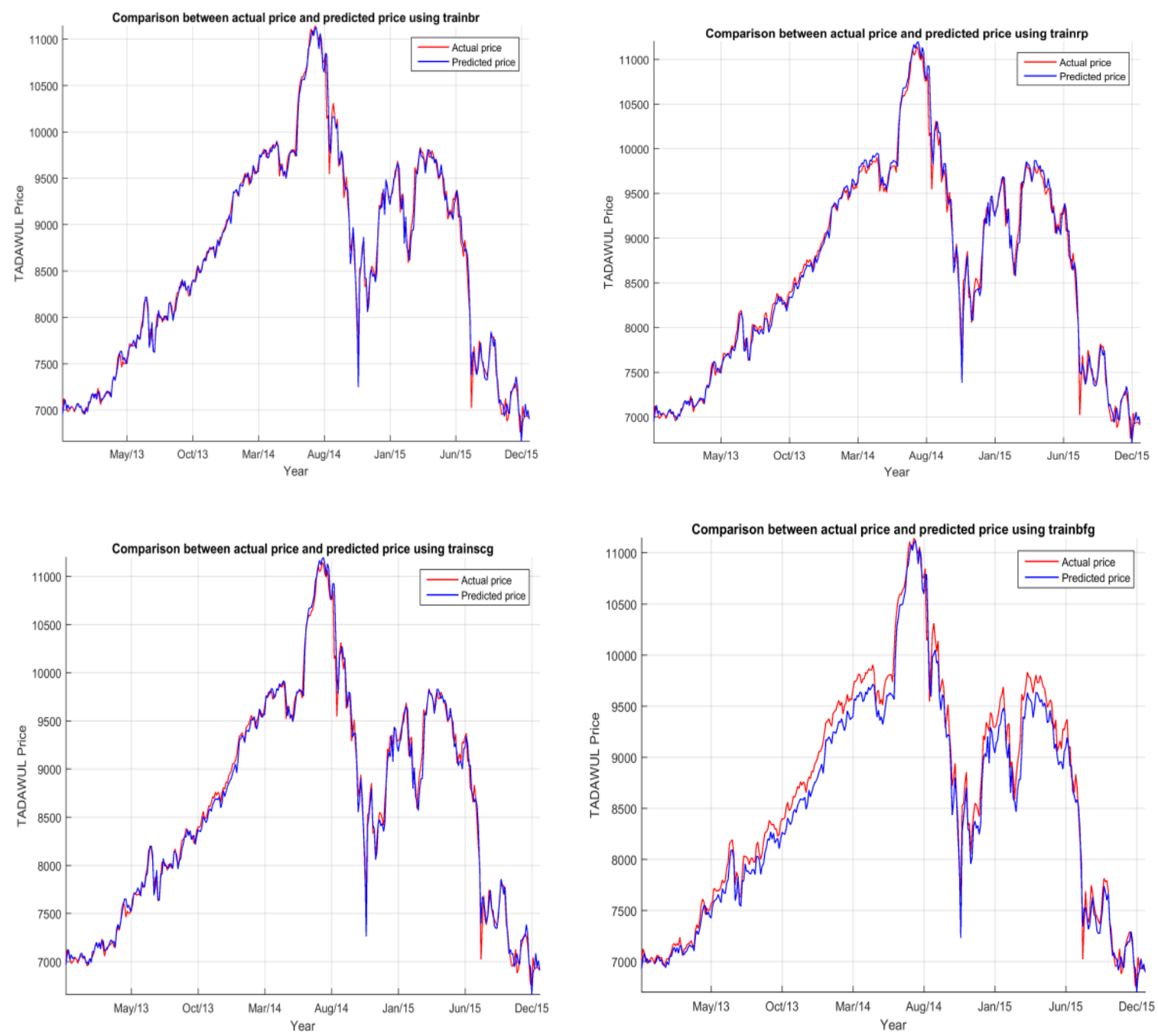

Figure 7. Comparison between actual and predicted price using trainbr, trainrp , trainbrscg and trainbfg 


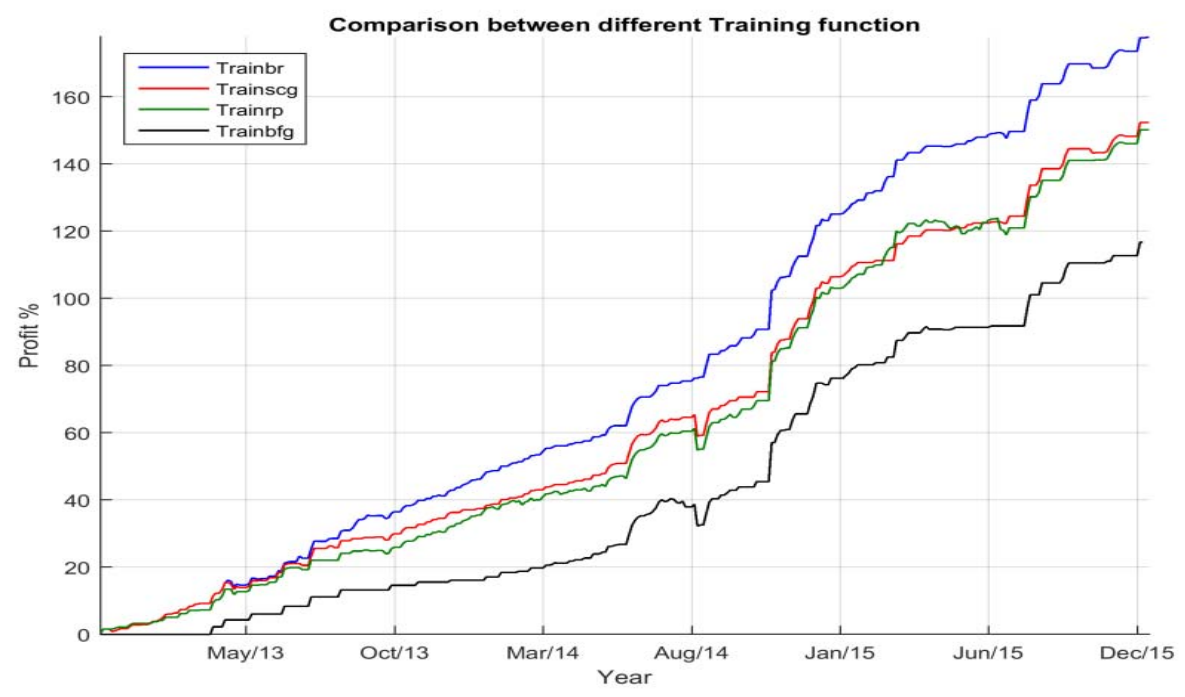

Figure 8. Profit achieved using different training function

\section{CONCLUSION}

Based on the research findings, the best input for predicting the movement of Saudi Market is Median price and Close Price(2 inputs). Further, the best training function is trainbr because it gives the highest accuracy, profit and provide the closest prediction between the predicted values and actual values when compared to other training functions. We conclude that neural network with back propagation has the potential to forecast and predict the stock market in a very effective way.

\section{REFERENCES}

[1] Jabin, S, Stock market prediction using feed-forward artificial neural network, International Journal of Computer Application (IJCA), 99(9),2014.

[2] Meshref, Hossam, Neural Networks, lecture nodes in Artificial Neural Networks, Taif, 2015

[3] Yao, J., \& Tan, C. L, A case study on using neural networks to perform technical forecasting of forex, Neurocomputing, 34(1), 79-98, 2000.

[4] Guresen, E., Kayakutlu, G., \& Daim, T. U, Using artificial neural network models in stock market index prediction, Expert Systems with Applications, 38(8), 10389-10397,2011.

[5] Majumder, M., \&Hussian, M. A, Forecasting of Indian stock market index using artificial neural network, Information Science, 98$105,2014$.

[6] Chen, A. S., Leung, M. T., \&Daouk, H, Application of neural networks to an emerging financial market: forecasting and trading the Taiwan Stock Index, Computers \& Operations Research, 30(6), 901-923., 2003

[7] Gupta, A., \&Dhingra, B, Stock market prediction using hidden Markov models. In Engineering and Systems (SCES), Students Conference on (pp. 1-4). IEEE,2012.

[8] Ou, P., \& Wang, H, Prediction of stock market index movement by ten data mining techniques, Modern Applied Science, 3(12), $\mathrm{p} 28,2009$.

[9] Kara, Y., Boyacioglu, M. A., \&Baykan, Ö. K, Predicting direction of stock price index movement using artificial neural networks and support vector machines: The sample of the Istanbul Stock Exchange. Expert systems with Applications, 38(5), 5311-5319,2011.

[10] El moufatich, Fayssal, Mathworks.com, Retrieved 15 july, 2010, from http://www.mathworks.com/matlabcentral/fileexchange/27907download-google-finance-stock-prices/content/googleprices.m

[11] Khoa, N. L. D., Sakakibara, K., \& Nishikawa, I, Stock price forecasting using back propagation neural networks with time and profit based adjusted weight factors, In SICE-ICASE, International Joint Conference(pp. 5484-5488). IEEE.,2006.

[12] Khashei, M., \&Bijari, M, An artificial neural network (p, d, q) model for timeseries forecasting, Expert Systems with applications, 37(1), 479-489.,2010.

[13] Chan, M. C., Wong, C. C., \& Lam, C. C, Financial time series forecasting by neural network using conjugate gradient learning algorithm and multiple linear regression weight initialization, In Computing in Economics and Finance (Vol. 61),2000.

[14] Nordberg, M., \&Karlsson, S, Stock market index prediction using artificial neural networks trained on foreign markets: And how they compare to a domestic artificial neural network., PhD Thesis, KTH , 2015.

[15] Ye, Q., \& Wei, L, The Prediction of Stock Price Based on Improved Wavelet Neural Network. Open Journal of Applied Sciences, 5(04), 115, 2015

[16] Chen, W. H., Shih, J. Y., \& Wu, S, Comparison of support-vector machines and back propagation neural networks in forecasting the six major Asian stock markets. International Journal of Electronic Finance, 1(1), 49-67,2006.

[17] Grigoryan, H, Stock Market Prediction using Artificial Neural Networks, Case Study of TAL1T, Nasdaq OMX Baltic Stock, Database Systems Journal BOARD, 14.,2015 


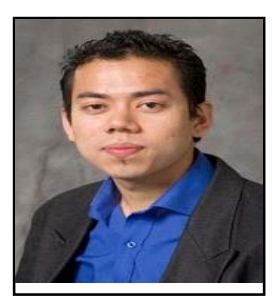

\section{AUTHORS PROFILE}

Amril Nazir, received the $\mathrm{PhD}$ degree in Computer Science from University College London (UCL) in 2011. His research interests include financial engineering, high performance computing, cloud computing, big data processing, machine learning, data mining, and embedded systems. He is an Assistant Professor at the Department of Computer Science, Taif University. Previously, he worked as a senior researcher at a government R\&D institute.

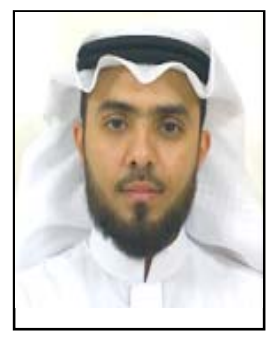

Roobaea Alroobaea is an assistant professor in College of Computers and Information Technology, Taif University, Kingdom of Saudi Arabia. He is a Chair of support researches and system at Deanship of scientific research in Taif University. He received his bachelor's degree in computer science from King Abdulaziz University (KAU) in Kingdom of Saudi Arabia, in 2008. He achieved a distinction in master's degree from the University of East Anglia in the United Kingdom, in 2011. Additionally, he received his PhD's degree in computer science from the University of East Anglia in the United Kingdom, in 2016. His research interests include cloud computing, big data processing, machine learning, data mining and IOT.

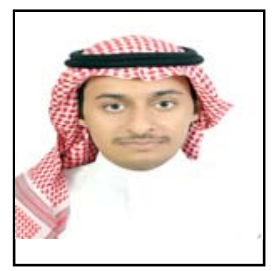

Talal Alotaibi earned a bachelor's degree in Computer Science from Taif University in 2016. Currently he is working at Accenture as Technology Consulting Analyst. His work interest is on data analytics and artificial intelligence. He is currently working on data analysis, data discrepancy, machine learning, data governance and data quality. 